\title{
COVID-19 E QUESTÕES ESTRUTURAIS: A TRANSFORMAÇÃO POR MEIO DO DIÁLOGO E DA COLABORAÇÃO
}

\author{
Thaís Cândido Lopes ${ }^{1}$ \\ Beatriz Carolina da Costa Sant'Ana ${ }^{2}$ \\ Lays Gabriela Cardoso ${ }^{3}$ \\ Mariana de Souza Rodrigues ${ }^{4}$ \\ Milene Moraes Almeida 5 \\ Rodrigo Santana Cardoso ${ }^{6}$ \\ Victor Vasques Ribeiro ${ }^{7}$ \\ Yasmin Defacio Saracho ${ }^{8}$ \\ Rafael de Araujo Arosa Monteiro ${ }^{9}$
}

Resumo: Neste artigo buscamos realizar a identificação dos valores vigentes promotores das desigualdades e violências, readmirá-los criticamente, para, então, propor novos valores e ações colaborativas que nos possibilitem transicionar para modelos de sociedades sustentáveis. Como resultado desse processo coletivo, identificamos valores ligados à desvalorização do não humano - outras espécies, mares, rios, solos, dentre outros, e à desvalorização do humano - racismo, machismo e homofobia, chegando à proposição da valorização da vida, valorização das pessoas negras, valorização das mulheres e valorização das pessoas LGBTQ+, propondo práticas para sua concretização por meio do diálogo e da colaboração.

Palavras-chave: COVID-19; Sociedades Sustentáveis; Diálogo.

\footnotetext{
${ }^{1}$ Coordenadora do Coletivo Jovem Albatroz. E-mail: thaislopes.ma@gmail.com.

Link para o Lattes: http://lattes.cnpq.br/2363551362679750

2 Integrante do Coletivo Jovem Albatroz. E-mail: 1992.beatriz@gmail.com.

Link para o Lattes: http://lattes.cnpq.br/9212828072185090

3 Integrante do Coletivo Jovem Albatroz. E-mail: laysc.bio@gmail.com.

Link para o Lattes: http://lattes.cnpq.br/4724290643315642

${ }^{4}$ Integrante do Coletivo Jovem Albatroz. E-mail: m.rodrigues6@gmail.com.

Link para o Lattes: http://lattes.cnpq.br/3063255873945952

5 Integrante do Coletivo Jovem Albatroz. E-mail: milene tur@hotmail.com.

6 Integrante do Coletivo Jovem Albatroz. E-mail: rodrigobio1994@gmail.com.

Link para o Lattes: http://lattes.cnpq.br/4765734380377305

7 Integrante do Coletivo Jovem Albatroz. E-mail: victorvasquesribeiro@outlook.com.

Link para o Lattes: http://lattes.cnpq.br/1530887375287181

8 Integrante do Coletivo Jovem Albatroz. E-mail: yasmindefacio@gmail.com.

Link para o Lattes: http://lattes.cnpq.br/5759956308453205

${ }^{9}$ Instituto de Energia e Ambiente - Universidade de São Paulo.

E-mail: rafael.araujo.monteiro@gmail.com. Link para o Lattes: http://lattes.cnpq.br/5585638635194187
} 
Abstract: In this article we seek to identify the values that promote inequalities and violence, review them critically, and then propose new values and collaborative actions that enable us to move towards models of sustainable societies. As a result of this collective process, we identified values linked to the devaluation of the nonhuman - other species, seas, rivers, soils, among others and the devaluation of the human - racism, male chauvinism and homophobia, arriving at the proposition of valuing life, valuing black people, valuing women and valuing LGBTQ+ people, proposing dialogue and collaboration as practical paths for its realization.

Keywords: COVID-19; Sustainable Societies; Dialogue.

\section{Introdução}

Este texto é fruto da reflexão das autoras(es), ligadas ao Coletivo Jovem Albatroz (CJA), o qual agrega dentro de si uma diversidade de olhares e experiências. Jovens de diferentes gêneros, cores, sexualidades, religiões e tantas outras características.

Essa diversidade é uma das maiores qualidades do Coletivo, possibilitando a todas(os) a realização do exercício dialógico, em que juntas(os) buscamos compartilhar nossas interpretações para identificar as concepções de mundo estabelecidas e, assim, poder repensá-las. As ideias gestadas coletivamente são, por sua vez, transformadas em intervenções educadoras que nos possibilitam o encontro com outros jovens, adultos, crianças e idosos com os quais queremos refletir e agir juntos em prol da transição para sociedades sustentáveis.

Nossa caminhada enquanto coletivo completou, em 2020, cinco anos. Muitas ideias, experiências e intervenções foram vividas, bem como momentos de frustração, desesperança e indignação. Jovens que somos, sempre ouvíamos as histórias de grandes momentos históricos da humanidade e como vivemos atualmente suas consequências. Eis que nos deparamos, pela primeira vez, com a experiência de uma pandemia, atravessada pela incerteza e pela incapacidade humana de controle sobre a situação.

Nesse contexto, as desigualdades e preconceitos estruturais se fizeram mais nítidos. O vírus da COVID-19 parece ter diminuído, pelo menos por enquanto, em alguns poucos graus a miopia ética de muitas pessoas. Parece que questões como pobreza, racismo, machismo, homofobia e tantas outras ficaram mais evidentes.

Provocados por muitas reflexões, destacamos as de Eliane Brum (2020), em que alerta para a disputa pelo período pós COVID-19. Para a autora o discurso de retorno a "'normalidade' é a defesa do privilégio de alguns poucos em detrimento da espoliação de muitos. 'O rompimento do 'normal', provocado pelo vírus, pode ser a oportunidade para desenhar uma sociedade baseada em outros princípios, capaz de barrar a catástrofe climática e promover justiça social'. 
É esse desenho de uma nova sociedade que nos mobilizou a realizar cinco encontros virtuais de diálogo de uma hora e meia cada, com base no procedimento metodológico sugerido por Monteiro e Sorrentino (2019), para identificar os valores "normais" vigentes, readmirá-los criticamente, propor novos valores e ações que estimulem sua materialização. Como resultado desse processo coletivo, identificamos valores ligados à desvalorização do não humano - outras espécies, mares, rios, solos, dentre outros, e à desvalorização do humano - racismo, machismo e homofobia, chegando à proposição de novos valores e sugerindo, por fim, caminhos para sua concretização. A seguir apresentamos em maiores detalhes essas ideias.

\section{A desvalorização do não humano}

Já conhecemos a implicação de nossos valores e comportamentos frente à conservação ambiental. Então, por que parece tão difícil a mudança? Será que, após a pandemia, alguma coisa irá mudar?

Estas são perguntas que rondam constantemente a mente de educadoras e educadores ambientais e de todos os interessados no assunto, pois as mudanças climáticas já estão interferindo na sobrevivência da humanidade e serão ainda mais intensas nos próximos anos, afetando a saúde ambiental de todos os seres vivos. Sabemos que a dicotomia entre os sistemas sociais e ecológicos causam a crise socioambiental que enfrentamos atualmente (FERNANDES; SAMPAIO, 2008) e, ainda, que comprometer a biodiversidade e suas interações ecológicas compromete a sobrevivência humana no planeta.

É preciso reconhecer que vivemos em uma sociedade desigual, de produção capitalista e que não distribui de forma igualitária o capital. Segundo Silva e Guimarães (2018), a sociedade atual se encontra desconectada e fragmentada, o que contribui para a continuidade das atividades capitalistas e reduz drasticamente a qualidade de vida ambiental de grande parcela da população e do planeta.

O Brasil é um país no qual a discussão sobre os assuntos socioambientais é historicamente complicada. Desde 1988, com a morte do ecologista Chico Mendes e o fato do Brasil ser considerado um dos países que mais mata ambientalistas (GLOBAL WITNESS, 2018), somos engolidos pelo princípio de "quem pode pagar mais se beneficia", tendo como política ambiental o favorecimento dos causadores de impacto, em um movimento de "(...) ir passando a boiada, ir mudando todo o regramento e simplificando normas" (G1, 2020). As ações e decisões socioambientais tomadas têm diversas implicações e aquelas que vêm sendo assumidas durante a pandemia parecem ser direcionadas ao fracasso.

Em paralelo, importantes problemas histórico-culturais, como o racismo, o machismo e a homofobia, frutos de valores preconceituosos, parecem ser escancarados pela pandemia. 


\section{A desvalorização do humano}

\section{Racismo}

O Brasil foi o último país da América do Sul a abolir a escravidão, sem colocar garantia de direitos ou indenização à população negra por tantos anos de trabalho forçado. Não houve políticas públicas que permitissem aos recém libertos acesso à educação ou a inserção ao mercado de trabalho de forma igualitária. Por meio de ações excludentes a sociedade ditava quais lugares poderiam ser ocupados por pessoas negras e indígenas e quais lugares poderiam ser ocupados por pessoas brancas, acarretando consequências até os dias atuais (SALLES, 2011). Por conta dessa herança colonial, é reproduzido cotidianamente ações racistas nos tempos atuais, dando espaço para a normalização do Racismo Estrutural.

De acordo com Silvio Luiz de Almeida (2018), Racismo Estrutural se refere ao racismo como uma relação social que permeia todas as esferas da vida, dando forma à estrutura social. Nesse sentido, define os padrões e as regras discriminatórias de raça, ditando a normalidade da sociedade e criando mecanismos para que pessoas ou grupo de pessoas brancas estejam ocupando um lugar de dominação e, portanto, de discriminação.

Em sua forma institucional, o racismo se faz presente na dinâmica das instituições, reproduzindo as condições de exclusão ou de privilégio de acordo com a raça (ALMEIDA, 2018). Mbembe (2014) afirma que racismo e raça são definidos pelo Estado, o qual justifica os seus aparatos de repressão e processos de injustiça por ele cometidos. Podemos analisar esses processos por meio do Atlas da Violência (IPEA; FBSP, 2019), o qual apresenta a relação entre homicídios no Brasil. Em uma amostragem dos 100 mil homicídios que ocorreram no ano de 2017, 49.525 representam pessoas negras, ao passo que 14.734 representam pessoas não negras. Assim, para cada indivíduo não negro que sofreu homicídio em 2017, aproximadamente, 2,7 negros foram mortos. O apontamento dos números não vem da necessidade de estimular uma competição entre negros e não negros, mas de analisar a estrutura de uma sociedade que todos os dias coloca homens e mulheres negras no índice de pessoas que mais morrem no Brasil.

Portanto, o racismo é a forma pela qual desqualificamos o outro e o anulamos como não semelhante. Colocando o outro como inerentemente inferior, culpado biologicamente pela própria situação. Assim, nosso racismo nos fez aceitar a pobreza e a vulnerabilidade de enorme parcela da população brasileira. Os dados apresentados nos mostram de que maneira o sistema capitalista/estatal se beneficia através do racismo estrutural e como os negros e não brancos são a base da pirâmide que sustenta todo esse movimento.

Como se não bastasse apresentar dados de como a população negra é diretamente afetada em diversas esferas, temos também outra questão que solidifica todo o discurso até o momento apresentado: o racismo ambiental e a saúde no Brasil. 
"Racismo ambiental" é um tema que surgiu no campo de debates e de estudos sobre justiça ambiental, um clamor inicial do movimento negro estadunidense e que se tornou um programa de ação do governo federal dos Estados Unidos das Américas (EUA), por meio da EPA - Environmental Protection Agency, sua agência federal de proteção ambiental. O conceito diz respeito às injustiças sociais e ambientais que recaem de forma desproporcional sobre etnias vulnerabilizadas (HERCULANO, 2014, p.2).

Desde então, tem se observado pelo mundo uma série de acontecimentos que expõem a seletividade de grandes empresas e do próprio Estado na forma de lidar com problemas ambientais de acordo com a população atingida. Essa série de fatores reforça as desigualdades sociais, como o saneamento básico precário, a insegurança alimentar e a dificuldade de acesso à assistência médica (JESUS, 2020), os quais aumentam o risco de exposição e contaminação de pessoas negras à COVID-19 nesse período de pandemia que estamos vivendo.

Como exemplo do resultado dessas múltiplas determinações, nos Estados Unidos, os dados são dramáticos. Em uma reportagem do Estadão, os dados apresentados mostraram que as pessoas de etnia negra, em Chicago, representam $70 \%$ dos casos de coronavírus. Embora apenas um terço da população de Lousiana seja afro-americana, aproximadamente $70 \%$ das pessoas que morreram neste estado são negras (JUNIOR, 2020).

Assim, nos parece essencial o reconhecimento e a compreensão do Racismo Estrutural, enquanto produto do modo de produção capitalista-estatal que contribui para uma sociedade em que a população negra ocupa um lugar de grupo social dominado, para que possamos ter condições de propor ações mais assertivas para a superação desse modelo societário.

\section{Machismo}

Outro fator importante de dominação e opressão é o gênero. Segundo Minayo (2005), as ritualizações do masculino como tomador de decisão e dominador sexual, de um lado, e do feminino como ser passivo e objeto de valor a ser usado, de outro, possuem origens culturais enraizadas no sistema patriarcal, no qual o homem reside no papel de poder. Morgante e Nader (2014) afirmam que o patriarcado determina toda a dinâmica social, inclusive domando o inconsciente individual de homens, mulheres e coletivos enquanto camadas sociais, conceito muito bem situado histórica e geograficamente.

Campos (2015) demonstra que estereótipos e pré-conceitos de gênero compõem uma base de atitudes discriminatórias e preconceituosas ao se tratar das mulheres, como em conclusões de que mulheres adolescentes são promíscuas e culpadas pelos estupros de que são vítimas; por ditos populares, 
como "mulher gosta de apanhar" ou "em briga de marido e mulher não se mete a colher"; e em casos de homens que acreditam na não necessidade desse grupo comporem o âmbito trabalhista, respondendo as tentativas com violência.

Nesse sentido, a dupla jornada está embutida na realidade de muitas mulheres, fazendo com que elas precisem conciliar tarefas domésticas com o trabalho formal pago, cravado em cima de falsos estereótipos de que afazeres domésticos têm relação estrita com a mulher e aliados às ideias de que mulheres são seres frágeis, belos, indefesos e incompletos (DUARTE, 2018).

Aspectos discriminatórios e violentos às mulheres percorrem vários caminhos em uma sociedade para que essa cultura continue se perpetuando exponencialmente. Em sua forma mais cruel, materializa o feminicídio, a morte da mulher por conta do seu gênero. Tal categoria de assassinato foi criada para dar visibilidade aos números e as diferentes formas de violência extrema às mulheres, possibilitando o reconhecimento jurídico a agressões praticadas contra elas (CAMPOS, 2015).

Toledo (2020) explica que, com a medida do isolamento social para combater a pandemia de COVID-19, mulheres ficam mais tempo confinadas ao ambiente doméstico, aumentando de forma alarmante as violências contra a mulher em diversos países. Segundo a autora, além do serviço essencial de combate à violência doméstica em tempos de pandemia, é de extrema importância que não ocorram subnotificações das denúncias neste período, uma vez que as estatísticas de violências apontam essa falha e, isso ocorre porque ao delatarem tais agressões as mulheres sentem medo de possíveis exposições ainda piores, como por exemplo, o assassinato.

\section{Homofobia}

Um terceiro fator de opressão diz respeito à sexualidade. A homossexualidade é considerada uma prática criminosa em 70 países ao redor do mundo, podendo ser punida inclusive com prisão perpétua ou pena de morte. Apesar disso, nos últimos anos, ocorreram grandes avanços desse grupo nos âmbitos social, político e legal, impulsionados por lutas individuais, regionais e de grandes organizações mundiais (MENDOS, 2019; ILGA, 2020).

As conquistas incluem, em vários países, a proteção total ou parcial dos homossexuais, por parte do estado, contra a violência e a discriminação. Entretanto, em alguns locais, a legislação e os dados da realidade da população LGBTQ+ são conflitantes entre si. Além disso, muitas das proteções legais abordam apenas orientação sexual, causando desafios ainda maiores para o recorte de identidade de gênero dentro da comunidade, como acontece com os transexuais (CASTEDO; TOMBESI, 2019).

Percebe-se no Brasil uma contraditória relação entre o que é legalmente aceito e a prática popular, ao passo que, dentre países 
reconhecidos pela Organização das Nações Unidas, o Brasil está entre os 26 que reconhecem o casamento entre pessoas do mesmo sexo e entre os 3 que proíbem "terapias de conversão", no entanto, o Brasil também se destaca no topo da lista de países que mais matam homossexuais (CASTEDO; TOMBESI, 2019). De acordo com Kelly Domingos, secretária de Políticas Sociais da Central Única dos Trabalhadores de São Paulo, a situação delicada da população LGBTQ+ ainda foi agravada após as eleições de 2018. Segundo Domingues, "o ministério (da Mulher, Família e Direitos Humanos) que deveria trabalhar com essa população tem uma ministra que acredita em "cura gay"' (CUT, 2019).

Segundo o Atlas da Violência (IPEA; FBSP, 2019), um dos maiores desafios no combate contra a desigualdade de direitos e violência vivenciada pela população LGBTQ+ é justamente o apagão estatístico causado pela falta de visibilidade da própria comunidade. A invisibilidade, por sua vez, é impulsionada pelo medo dos homossexuais de se expor à violência. $O$ medo é justificado, pois, ainda de acordo com o Atlas da Violência, a própria sigla LGBTQ+ conta com o símbolo de adição a fim de dar visibilidade para casos de assassinatos de heterossexuais que foram vítimas de homofobia ao serem confundidos com homossexuais. Sendo assim, é notável como o crime de ódio se estende não somente para quem é homossexual, mas também para quem parece ser.

Ainda no âmbito político, a pesquisa Violência contra LGBTQ+ nos contextos eleitoral e pós-eleitoral (BULGARELLI; FONTGALAND, 2019) foi composta pela aplicação simultânea de questionários no Rio de Janeiro, Salvador e São Paulo. O estudo entrevistou um total de 400 pessoas, em locais sabidamente frequentados pela população LGBTQ+. Os questionários visavam elucidar e fornecer dados sobre dois temas: a violência contra LGBTQ+ no período eleitoral e a violência contra LGBTQ+ nas redes sociais. Os resultados da pesquisa foram alarmantes: $51 \%$ dos entrevistados relataram haver sofrido algum tipo de violência durante e após as eleições de 2018. Dentre as respostas, destacaram-se com alto índice: violência verbal, tratamento discriminatório e assédio moral. A violência física foi citada em 13\% dos relatos. Esses números demonstram o impacto do discurso conservador nas massas, que rapidamente se acomodam em serem guiadas por valores morais conservadores. A facilidade com a qual esse tipo de valor se infiltra na sociedade, a despeito da legislação vigente de proteção à comunidade LGBTQ+, traz a percepção da presença de uma estrutura social heteronormativa, que não pode ser fragmentada tão facilmente.

No contexto da pandemia de COVID-19, Sato et al. (2020) trazem reflexões sobre a inclusão da população LGBTQ+ no grupo vulnerável. Apontaram que líderes religiosos ao redor do mundo relacionaram o surgimento do vírus ao avanço de pautas identitárias de igualdade de sexo e gênero. A técnica usada por estes líderes não é inédita, uma vez que outrora a pandemia de peste negra foi creditada aos homossexuais (TESTONI, 2020). 
Sato et al. (2020) ressaltam que o isolamento social pode se tornar muito mais desafiador, isto porque muitos homossexuais não têm, por variados motivos, vínculos afetivos com suas famílias. Além disso, evidencia as dificuldades de muitos transexuais e travestis que, por falta de oportunidade, são obrigados a recorrer à prostituição e, em momentos como esse, acabam enfrentando a redução de renda, maior vulnerabilidade à transmissão de COVID-19 e discriminação no sistema de saúde.

Por fim, em um comunicado histórico, a Organização das Nações Unidas (2020), emitiu um alerta internacional para que os governos estejam preparados para garantir a participação da comunidade LGBTQ+ na definição das medidas e políticas públicas adotadas no combate à COVID-19. O documento, que foi firmado por 96 peritos em direitos humanos, admite que alguns países estão usando a pandemia como pretexto para perseguições, práticas discriminatórias e atos de violência. Segundo o documento "as pessoas lésbicas, gays, bissexuais, trans e gênero-diversas estão desproporcionalmente representadas entre pobres, pessoas em situação de rua e que não têm atenção médica e serão profundamente afetadas pela pandemia. A menos que tomemos medidas urgentes, este impacto será sentido por gerações" (tradução nossa).

\section{Novos valores para sociedades sustentáveis: o desenho da utopia}

O desafio está posto e é enorme. Seu reconhecimento é um primeiro passo importante no processo de transformação. A partir disso, novos valores devem ser nutridos no processo de transição para sociedades sustentáveis. Vamos a eles.

\section{A valorização da vida}

Muitos valores, opiniões, preconceitos e existências foram escancarados e, ao mesmo tempo, foi observado durante essa quarentena mundial, como sugeriu Latour (2020), que é possível transformar o modelo de progresso vigente, sendo desnecessária a nossa obsessividade em consumir todos os recursos naturais.

A pandemia e 0 isolamento social nos oferecem a oportunidade de repensar nossos valores e atitudes em relação ao meio ambiente e a nós e nos questionar sobre o mínimo que precisamos para uma vida digna.

As medidas adotadas, a partir do isolamento mundial, têm mostrado rápidas e visuais melhoras nos ambientes naturais, seja em "céus mais azuis" causados pela redução da emissão de nitrogênio (N2) e dióxido de carbono (CO2) devido a diminuição de veículos automotores e processos industriais, como também em "corpos d'água mais transparentes", consequência de menor número de turistas e dejetos, ou ainda em uma "fauna menos intimidada" pelos 
poluentes e atividades turísticas, como golfinhos avistados próximos ao porto de Cagliari, na Itália (UFJF, 2020).

Dessa forma, vislumbramos a possibilidade de real enfrentamento e transformação dos principais problemas da atualidade que mais impactam a sociobiodiversidade, como as mudanças climáticas, o adensamento urbano, a modificação de hábitats, a exploração de recursos naturais e a poluição, fomentando a valorização da vida num processo de transição para sociedades sustentáveis.

\section{A valorização das pessoas negras}

Silvio Almeida (2018. p.65) afirma que

o racismo constitui todo um complexo imaginário social que a todo momento é forçado pelos meios de comunicação, pela indústria cultural e pelo sistema educacional. Após anos vendo telenovelas brasileiras, um indivíduo vai acabar se convencendo de que mulheres negras têm uma vocação natural para o trabalho doméstico, que a personalidade de homens negros oscila invariavelmente entre criminosos e pessoas profundamente ingênuas, ou que homens brancos sempre tem personalidades complexas e são líderes natos, meticulosos e racionais em suas ações. E a escola reforça todas essas percepções ao apresentar um mundo em que negros e negras não têm história, literatura, ciência e afins, limitando-se a comemorar a própria liberação graças à bondade de brancos conscientes.

Dessa forma, é de grande relevância a reflexão sobre tal imaginário social, reconhecendo e valorizando a vida das pessoas negras na nossa sociedade. Para isso, podemos levantar uma série de questionamentos, como: É possível pensar em música brasileira sem música negra? É possível pensar em dança brasileira sem dança negra? É possível pensar em arte plástica brasileira sem pensar na contribuição dos negros e negras? É possível pensar em ciência brasileira sem pensar na contribuição dos negros e negras?

Parece-nos impossível. Durante muito tempo se tentou negar a contribuição de negros e negras para a nossa riqueza espiritual e intelectual. Como consequência, tem-se 0 apagamento e o esquecimento das contribuições do ser africano na construção da história brasileira. Internalizamos o racismo no Brasil. São muitos anos de escravidão e ela ainda continua. Fomos ensinados a ser racistas. Não se trata de uma vontade de sêlo, mas de reproduzir comportamentos sociais que definem a nossa história e moldam a nossa sociedade, negando muitas pessoas e sua origem negra. 
Isso é cruel. Esta história não é contada. Para saber a respeito é necessário pesquisar, ter a vontade individual de ir atrás e tentar entender. Inserir negros e negras como protagonistas em todos os espaços que ocupam é valorizar a sua história e sua cultura. É repensar as estruturas e compreender que a nossa nação não é apenas negra em números, mas em dados históricos que movimentam até hoje diversos cenários no Brasil. Por fim, valorizar a cultura negra é também uma forma de reescrever uma história que por muitos anos silenciou, oprimiu e diminuiu um povo que sofre as consequências até os dias atuais.

\section{A valorização da mulher e a defesa de posturas antimachistas}

Em combate ao machismo estrutural, defendemos uma nova forma de sociedade, buscando, como sugerem Oliveira e Cassab (2014), novos conceitos e identidades políticas, denunciando as desigualdades para garantir os direitos das meninas e das mulheres.

Defendemos novas formas e perspectivas antimachistas de se analisar o mundo, baseadas nos preceitos da economia feminista (FERBER; NELSON, 1993; FOLBRE, 1998; CASTRO-GOMEZ; GROSFOGUEL, 2007 apud HILLENKAMP 2014; CARRASCO, 2005), permitindo elucidar questões que são tradicionalmente mantidas ocultas.

Para a superação das desigualdades e violências de gênero, nos parece necessário considerar, portanto, os modos de vida e a visão de mundo das mulheres em todos os âmbitos políticos e, assim, fomentar políticas públicas, através da perspectiva da economia feminista, que estejam a serviço e sejam realizadas em prol da vida das mulheres e de todas(os).

\section{A valorização da identidade da comunidade $L G B T Q_{+}$}

Considerando que o relacionamento entre pessoas do mesmo sexo nem sempre foi visto como antinatural, que a prática chegou a ser considerada por Sócrates como algo inspirador e que os melanésios possuíam em sua cultura ritos nos quais um homem transvestido representava um espírito alegre, somos levados a nos questionar em que momento surgiu e para quais interesses a discriminação serve.

Nos questionamos também quantas vidas foram apagadas ou prejudicadas pela prática discriminatória que surgiu após a fé cristã se popularizar, pregando o sexo apenas como forma de procriação.

Nos questionamos sobre o quanto deixamos de explorar mais a genialidade de figuras como Alan Turing e Oscar Wilde, que mesmo tendo sido perseguidos e punidos por serem homossexuais, deixaram grandes legados para a humanidade. Quantos grandes feitos deixamos de ver na história, apenas por discriminação? 
É por isso que defendemos uma realidade mais igualitária e justa para todos e práticas educacionais que estimulem a autoaceitação, a construção de um pensamento crítico e a substituição de modelos tradicionais por modelos inclusivos, que não só entendam como vital a igualdade de direitos fundamentais, quanto percebam com admiração a existência das diferenças e liberdades individuais.

\section{Práticas para a transformação}

Com base no exposto até aqui e no entendimento da urgência de uma sociedade que se coloque efetivamente através de práticas antidestrutivas, antirracistas, antimachistas e antihomofobicas, listamos abaixo algumas formas individuais e coletivas para se chegar nessa transformação:

- Reconhecer a desvalorização da vida, o racismo, machismo e homofobia presentes na sociedade brasileira, e consequentemente, os problemas que eles causam;

- Entender que a desvalorização da vida, o racismo, machismo e homofobia são questões estruturais ligadas ao sistema capitalista vigente, sendo necessária uma transformação sistêmica;

- Buscar a constante autorreflexão sobre a desvalorização da vida, o racismo, o machismo e a homofobia na sociedade;

- Reconhecer e desconstruir privilégios, buscando entender sua construção história e como beneficiam muitos na mesma medida em que afetam negativamente outros;

- Reconhecer e aceitar que a branquitude foi educada para se perceber enquanto humano e não enquanto pessoas brancas, colocando como regra padrões e normas que são reproduzidos na sociedade;

- Ter coragem e disposição para enfrentar os incômodos, estranhamentos e desconfortos frutos do reconhecimento de privilégios;

- Não se acomodar em situações em que surgem a desvalorização da vida, o racismo, o machismo e a homofobia e refletir de forma crítica como o homem branco heterossexual se constrói na sociedade;

- Não se acomodar numa equivocada interpretação do lugar de fala, em que se acredita que somente os negros e indígenas tem o que dizer sobre como enfrentar o racismo, que apenas as mulheres têm o que dizer sobre como enfrentar o machismo e as LGBTQ+ têm o que dizer sobre como enfrentar a homofobia. Os homens brancos heterossexuais importam nas lutas antirracistas, antimachistas e antihomofóbicas, auxiliando no processo de desconstrução de uma sociedade que oprime 
minorias e cuidando para não desqualificar, invisibilizar ou negar o protagonismo dessas lutas sociais com seus privilégios;

- Ter a responsabilidade e comprometimento com ações que promovam efetivamente o fim da desvalorização da vida, do racismo, do machismo e da homofobia;

- Repensar e redesenhar políticas públicas destinadas à natureza, às negras, aos negros, às mulheres e às LGBTQ+;

- Repensar e refletir sobre nossos hábitos de consumo e suas consequências na valorização da vida no planeta;

- Estimular e apoiar a auto-organização dos oprimidos, como movimentos sociais e suas práticas;

- Valorizar e inserir pessoas negras, do gênero feminino e LGBTQ+ em todos os nichos do mercado de trabalho;

- Inserir dentro de instituições processos formativos que promovam a discussão do racismo, do machismo e da homofobia institucional, tendo como caráter importante a participação de pessoas negras, não negras e brancas;

- Inserir na educação a história da população negra como uma das formas de democratização da cultura;

\section{Diálogo e colaboração: caminhos para fortalecer a transformação}

Para a materialização das práticas supracitadas, sugerimos a constituição de grupos virtuais de diálogo que possibilitem às pessoas 0 reconhecimento das diferenças, fruto das trajetórias de vida individuais inseridas em contextos sociais particulares, para, então, podermos superar 0 cenário de polarização generalizada e construímos coletivamente o futuro desejado.

O diálogo aqui defendido não é uma prática ingênua de se sentar com pessoas e simplesmente tentar conversar para se chegar a acordos. $O$ que propomos aqui se alinha à concepção apresentada por Monteiro e Sorrentino (2019), em que colocam o diálogo como uma forma de se comunicar com o outro, que oportuniza às pessoas pensarem em conjunto, possibilitando o surgimento de novas compreensões sobre os modos de viver a vida para, então, construir ações articuladas e colaborativas.

E como operacionalizar tais encontros?

Propomos a realização de tantos grupos de diálogo quanto necessário para atingir o maior número de pessoas. Nesse momento de isolamento devem ocorrer em ambientes virtuais, por meio de software de videoconferência. $O$ procedimento metodológico a ser adotado é o sugerido por Monteiro e Sorrentino (2019, p. 37), composto por quatro momentos: "(1) codificação; (2) observação da codificação ou escuta genuína; (3) descrição da codificação; (4) 
're-admiração' das admirações, observando as sensações corporais e emoções e analisando criticamente todo o processo".

A codificação se caracteriza pela representação de algum aspecto da realidade, ganhando forma por meio da fala de uma pessoa, por fotografias, por pinturas, por vídeos, enfim, por uma série de caminhos. Conforme vamos recebendo a informação nos deixamos ser tomadas(os) por ela, focando nossa atenção para observá-la/escutá-la genuinamente. Em seguida, inicia-se a descrição da codificação, em que cada pessoa compartilha seus pensamentos, suas sensações corporais, seus sentimentos e suas dúvidas sobre aquilo que se está conversando. Com o caminhar do processo, é possível começar a (re)admirar as admirações, buscando compreender a maneira pela qual pensamos e agimos, a partir do contato com as formas de pensar e agir do outro (MONTEIRO; SORRENTINO, 2019) e, assim, fomentar a criação de novos sentidos e ações colaborativas (JACOBI; MONTEIRO; SOUZA, 2020).

Para que tal proposta ganhe escala, sugerimos o aproveitamento do potencial de capilarização (ÓRGÃO GESTOR DA PNEA, 2006) do diálogo, o qual está presente nas próprias pessoas que participam dos grupos virtuais, uma vez que poderão exercitar e fomentar a dialogicidade com quem interagem e convivem cotidianamente, como familiares, amigos e colegas de trabalho.

Por fim, reconhecemos que, por se tratar de um processo estimulador de mudanças estruturais, a transformação é lenta, dependendo do tempo de cada indivíduo para readmirar e mudar sua visão de mundo. Sendo assim, reafirmamos a necessidade de se garantir os direitos básicos de todos os seres humanos e não humanos enquanto o processo dialógico de transformação cultural ocorre, uma vez que sem a garantia dos direitos de maneira imediata, as populações vulneráveis são obrigadas a lidar com as externalidades do processo de transformação dos privilegiados. Ou seja, são forçadas a lidar com a discriminação e violência, enquanto a mudança se processa.

Sendo assim, nos inspiramos na ideia de Poder Dual, de Ervin (2015), para propor a criação de movimentos/coletividades de auto-organização dos oprimidos para transformar a sociedade de dominação, a partir de estratégias como a autossuficiência alimentar, as assembleias populares, o controle dos territórios que ocupam, a criação de espaços educativos nãoinstitucionalizados, as cooperativas e as redes de comunicação populares. Assim, estaremos, ao mesmo tempo, deslegitimando a institucionalidade opressora e criando uma sociedade emancipada.

Por fim, reconhecemos uma possível insuficiência das proposições feitas acima. Ou seja, de tais estratégias não serem suficientes, por si só, para dar conta de superar a problemática exposta aqui. Dessa forma, é preciso pensar e integrar outros caminhos para garantir a efetividade de um processo de transição para sociedades sustentáveis. Por isso, saudamos a iniciativa da Revista Brasileira de Educação Ambiental em organizar esse volume especial e 
esperamos que propostas complementares sejam apresentadas para que nós, educadoras e educadores ambientais, possamos juntas(os) contribuir com a transformação almejada.

\section{Referências}

ALMEIDA, S. L. O que é racismo estrutural? Belo Horizonte: Letramento, 2018.

BRUM, E. O futuro pós-coronavírus já está em disputa. El país Brasil, 2020. BULGARELLI, L.; FONTGALAND, A. Violência contra LGBTS+ nos contextos eleitoral e pós-eleitoral. Gênero e Número, 2019. Disponível em: $<$ http://violencialgbt.com.br/> Acesso em: 10 jun. 2020.

CAMPOS, C. H. Feminicídio no Brasil: uma análise crítico-feminista. Sistema Penal \& Violência, v. 7, n. 1, p. 103-115, 2015.

CARRASCO, C. Introdução: Para uma economia feminista. SOF - Sempreviva Organização $\quad$ Feminista, $2005 . \quad$ Disponível em: <http://www.sof.org.br/ref texto.htm> Acesso: 10 de junho de 2020.

CASTEDO, A.; TOMBESI, C. Mapa mostra como a homossexualidade é vista pelo mundo. BBC News Mundo, 2019. Disponível em: $<$ https://www.bbc.com/portuguese/internacional-48801567> Acesso em: 10 jun. 2020.

CUT. Brasil segue no topo dos países onde mais se mata LGBTs. 2019. Disponível em: <https://sp.cut.org.br/noticias/brasil-segue-no-topo-dos-paisesonde-mais-se-mata-lgbts-4d85> Acesso em: 10 jun. 2020.

DUARTE, G.; SPINELLI, L. M. Mulheres No Mundo Do Trabalho: dupla jornada, desigualdade salarial e assédio. VII Seminário Corpo, Gênero e Sexualidade. Universidade Federal do Rio Grande: 2018.

ERVIN, L. K. Anarquismo e Revolução Negra. Sunguilar, 2015.

FERNANDES, V.; SAMPAIO, C. A. C. Problemática ambiental ou problemática socioambiental? A natureza da relação sociedade/meio ambiente. Desenvolvimento e Meio Ambiente, n. 18, 2008.

G1. Ministro do Meio Ambiente defende passar "a boiada" e "mudar" regras enquanto atenção da mídia está voltada para a Covid-19. Disponível em: $\quad<$ https://g1.globo.com/politica/noticia/2020/05/22/ministro-do-meioambiente-defende-passar-a-boiada-e-mudar-regramento-e-simplificarnormas.ghtml> Acesso em 10 jun. 2020.

GLOBAL WITNESS. A que preço? Negócio irresponsáveis e assassinato de defensores da terra e do meio ambiente em 2017. Londres: Global Witness, 2018. 
HERCULANO, S. Racismo Ambiental: o que é isso? 2014. Disponível em: $<$ https://www.researchgate.net/publication/266344253 racismo ambiental o q ue e isso >, acesso em 08/01/2019

HILLENKAMP, I.; GUÉRIN, I.; VERSCHUUR, C. Economia Solidária e as teorias feministas: possíveis caminhos para uma convergência necessária. 2014. Disponível em: <http://www.sof.org.br/wp-content/uploads/2016/10/aeconomia-solidaria-e-as-teorias-feministas.pdf>. Acesso em 12 jun. 2020.

ILGA. THE INTERNATIONAL LESBIAN, GAY, BISEXUAL, TRANS AND INTERSEX ASSOCIATION. 2020 <https://ilga.org/> Acesso em: 10 jun. 2020.

IPEA; FBSP. ATLAS DA VIOLÊNCIA 2019. Brasília: Rio de Janeiro: São Paulo: Instituto de Pesquisa Econômica Aplicada; Fórum Brasileiro de Segurança Pública, 2019. Disponível em: $<$ https://www.ipea.gov.br/atlasviolencia/arquivos/downloads/6537atlas2019.pdf> Acesso em: 10 jun. 2020.

JACOBI, P. R.; MONTEIRO, R. A. A.; SOUZA, D. T. P. Caminhos para um nova ética em tempos pós COVID-19: o desafio de ampliar diálogos e fortalecer aprendizagem social. In: SOBRINHO, L. L. P.; CALGARO, C.; ROCHA, L. S. (Org.) COVID-19: direitos humanos e educação. Itajaí: UNIVALI, 2020.

JESUS, V. Racializando o olhar (sociológico) sobre a saúde ambiental em saneamento da população negra: um continuum colonial chamado racismo ambiental. Saúde e Sociedade, v. 29, 2020.

JUNIOR, G. Negros americanos também estão mais expostos ao coronavírus. O Estado de São Paulo, 2020. Disponível em: $<$ https://saude.estadao.com.br/noticias/geral,negros-americanos-tambemestao-mais-expostos-ao-coronavirus,70003291483 >. Acesso em: 10 jun. 2020.

LATOUR, B. Imaginar gestos que barrem o retorno da produção pré-crise. Tradução: Débora Danowski e Eduardo V. Castro. 2020. Disponível em: $<$ https://n-1edicoes.org/008-1> Acesso em: 12 jun. 2020.

MBEMBE, Achille. A crítica da Razão Negra. Tradução de Marta Lança. Lisboa: Antígona, 3. ed, 2014.

MENDOS, L. R. State-Sponsored Homophobia. ILGA, 2019.

MINAYO, M. C. S. Laços perigosos entre machismo e violência. Ciência \& Saúde Coletiva, v. 10, 2005.

MONTEIRO, R. A. A.; SORRENTINO, M. O Diálogo na Educação Ambiental: uma Síntese A Partir de Martin Buber, David Bohm, William Isaacs e Paulo Freire. Pesquisa em Educação Ambiental, v.14, n.1, 2019.

MORGANTE, M. M.; NADER, M. B. O patriarcado nos estudos feministas: um debate teórico. Anais.... XVI Encontro Regional de História da ANPUH, 2014. 
OLIVEIRA, L. P. R.; CASSAB, L. A. O movimento feminista: algumas considerações bibliográficas. Anais... III Simpósio Gênero e Políticas Públicas. Universidade Estadual de Londrina, 2014.

ORGANIZAÇÃO DAS NAÇÕES UNIDAS. COVID-19: The suffering and resilience of LGBT persons must be visible and inform the actions of States. $<$ https://www.ohchr.org/EN/NewsEvents/Pages/DisplayNews.aspx?NewsID=25 884\&LanglD=E> Acesso em: 10 jun. 2020.

ÓRGÃO GESTOR DA PNEA. Programa nacional de formação de educadoras(es) ambientais: por um Brasil educado e educando ambientalmente para a sustentabilidade. Brasília, DF, 2006.

SALLES, R. Abolição no Brasil: resistência escrava, intelectuais e política (1870-1888). Revista de Índias, v. 71, n. 251, p. 259-284, 2011.

SATO, M. et al. Os condenados da pandemia. Cuiabá: GPEA-UFMT \& Ed. Sustentável, 2020.

SILVA, C. C. M.; GUIMARÃES, M. Mudanças climáticas, saúde e educação ambiental como política pública em tempos de crise socioambiental. Revista de Políticas Públicas. v. 22, 2018.

TESTONI, M. Como na Peste Negra, Covid-19 põe em risco homossexual, $\begin{array}{llll}\text { prostituta } & \text { e } & \text { gato. Universa UOL, } 2020 .\end{array}$ <https://www.uol.com.br/universa/noticias/redacao/2020/05/03/como-na-pestenegra-Covid-19-poe-em-risco-homossexuaisprostitutas-egato.htm?aff source $=56$ d95533a8284936a374e3a6da3d7996 $>$ Acesso em 10 jun. 2020.

TOLEDO, E. O aumento da violência contra a mulher na pandemia de Covid-19: um problema histórico. Fiocruz, 2020. Disponível em: $<$ http://coc.fiocruz.br/index.php/pt/todas-as-noticias/1781-o-aumento-da-

violencia-contra-a-mulher-na-pandemia-de-covid-19-um-problemahistorico.htm|\#.XuPZAkVKjlU>. Acesso em: 12 jun. 2020.

UFJF. Pandemia e Meio Ambiente: Impactos momentâneos ou nova normalidade? 2020. Notícias UFJF. Disponível em: $<$ https://www2.ufjf.br/noticias/2020/04/24/pandemia-e-meio-ambiente-impactosmomentaneos-ou-nova-normalidade/>. Acesso em 6 jun. 2020. 